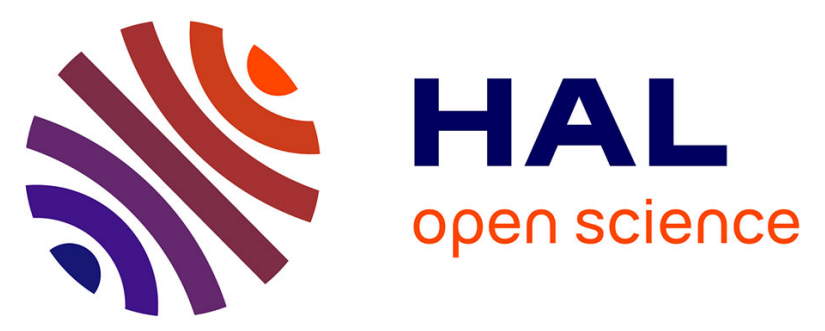

\title{
Image Analysis as a Tool to Age Estimations in Fishes: An Approach Using Blue Whiting on ImageJ
}

Patrícia Gonçalves, Vitor Silva, Alberto G. Murta, António Melo, Henrique Cabral

\section{- To cite this version:}

Patrícia Gonçalves, Vitor Silva, Alberto G. Murta, António Melo, Henrique Cabral. Image Analysis as a Tool to Age Estimations in Fishes: An Approach Using Blue Whiting on ImageJ. 8th Doctoral Conference on Computing, Electrical and Industrial Systems (DoCEIS), May 2017, Costa de Caparica, Portugal. pp.167-174, 10.1007/978-3-319-56077-9_15 . hal-01629601

\section{HAL Id: hal-01629601 https://hal.inria.fr/hal-01629601}

Submitted on 6 Nov 2017

HAL is a multi-disciplinary open access archive for the deposit and dissemination of scientific research documents, whether they are published or not. The documents may come from teaching and research institutions in France or abroad, or from public or private research centers.
L'archive ouverte pluridisciplinaire HAL, est destinée au dépôt et à la diffusion de documents scientifiques de niveau recherche, publiés ou non, émanant des établissements d'enseignement et de recherche français ou étrangers, des laboratoires publics ou privés.

\section{(c)(1)}

Distributed under a Creative Commons Attribution| 4.0 International License 


\title{
Image Analysis as a Tool to Age Estimations in Fishes: An Approach Using Blue Whiting on ImageJ
}

\author{
Patrícia Gonçalves ${ }^{1,2}$, Vitor Vaz da Silva ${ }^{3,4}$, Alberto G. Murta ${ }^{1}$, António Ávila de \\ Melo $^{1}$ and Henrique N. Cabral ${ }^{2}$ \\ ${ }^{1}$ Departamento do Mar e Recursos Marinhos, IPMA, Lisboa, Portugal \\ ${ }^{2}$ MARE, FCUL, Lisboa, Portugal \\ ${ }^{3}$ Instituto Superior de Engenharia de Lisboa, ISEL-IPL, Lisboa, Portugal \\ ${ }^{4} \mathrm{CTS}$ - UNINOVA, Caparica, Portugal \\ patricia@ipma.pt, vsilva@deetc.isel.ipl.pt
}

\begin{abstract}
Otoliths are the fish bones that allow it to hear sounds and achieve balance. The otolith grows in size as fish grows; ring bands are formed in the otoliths' surface registering periods of rapid and slow growth, opaque bands appear alternating with translucent bands. Age classification was made considering the number of translucent rings in the otolith; one translucent ring was equivalent to one year. The modeling of fish species abundance on the majority of fisheries assessment use age based models. The task of ring counting and ageing is time consuming and may introduce errors that can have a strong impact in stock assessment results. Thus, accurate and precise age estimates are crucial for the effective management and understanding of fisheries resources because recruitment dynamics, growth and mortality estimates relies on these data. The main goal of this study is to produce automatic reading procedures to help researchers, ageing blue whiting fish, minimize ring error count and improve accuracy and prevision on age estimation.
\end{abstract}

Keywords: Otoliths, fish ageing, image analysis, image processing, blue whiting and fisheries science.

\section{Introduction}

Otoliths are constituted by three pairs of calcareous structures, the sagittae, lapilli and asterisci, which are found in the inner ear. At the end of the 1960s and the beginning of the 1970s, sagittae otoliths started to be used for age determination and to study the feeding relationships between fish predators and their prey [1]. Since then the modeling of fish species abundance on the majority of fisheries assessment relies on age based models. Accurate and precise age estimates are critical for the effective management and understanding of fisheries resources because dynamic rates of recruitment, growth and mortality depend on these data [2].

Age classification has been based in age readings under stereo-microscopic observation. The interpretation of age reading is a very difficult task and may change among different readers or as a reader becomes more experienced [3]. Regularly, calibration age reading workshops are conducted aiming the improvement of accuracy

adfa, p. 169, 2011.

(C) Springer-Verlag Berlin Heidelberg 2011 
and precision of age estimations between the readers of the same species. Quality assurance in the ageing process guarantees the consistency which is uniquely important to this type of research work [4]. The criteria used to count the rings and determine age are made to be objective, but the final classifications are always dependent on the reader's experience, which introduces an interpretation error in the process [5]. This interpretation error can be either biased or random. In combination, process and interpretation error can result in age estimates that may differ by as much as a factor of three among readers [6].

There is an urgent need to validate and calibrate the currently age reading procedure within more effective automatic classification, in order to avoid subjective, and misinterpretation among readers. The image analysis constitutes a valuable tool applied to otoliths ageing and the recorded images allow performing simultaneously other studies, such as age validation. Several image analysis programs had been adapted in order to allow automatic count of daily increments such as RATOC [7], Image Pro Plus [8] and TNPC [9] and also annually increments like Image Pro Plus, TNPC, CAF [10] and ImageJ [11]. Although, the majority of the programs requires a license and is expensive, ImageJ has the advantage of being free software which allows record macros making simple and plug-ins that add algorithms to improve species ageing classifications.

The aim of this study is to improve ageing classifications through image analysis making the process based in more objective criteria. In order to achieve that goal a plug-in has been written and added to ImageJ. The otoliths used to test this new approach are from the blue whiting (Micromesistius poutassou) and the preliminary results are presented here. This study has been developed in order to know if: ImageJ could be used as an approach to improve the accuracy and precision of blue whiting ageing estimation?

\section{Contribution to Smart Systems}

In fisheries, for stock assessment annually a huge number of otoliths are read and the data for different countries combined. As an example, concerning the blue whiting stock, in 2015, around 102,000 fishes were measured and from these around 30,000 otoliths were processed for age reading, comprising data from 16 countries [12]. The consistent application of the ageing method over years, among readers, and even among laboratories (countries), is a particular requirement of stock assessment studies [2]. The inter-calibration workshops conducted regularly aim to guarantee that these age data can be combined and all the readers, from the different countries, follow the same criteria. The criteria for age estimation, based on ring counts, is defined to be easy to follow and objective. In practice, the accuracy and precision on age classifications is always dependent on the reader experience which reveal some subjectivity on the criteria. The age reading protocols based on images observations, is time consuming and based on decisions which can differ according to the reader experience.

The increasing demand on fisheries science to produce more data, the time involved and the ageing criteria mostly based on human decision, created the require- 
ments to searching new technologies applied to age reading estimation. These new technologies should be easy to apply and available to a wide range of scientists.

The otolith grows in size as fish grows; ring bands are formed in the otoliths surface registering periods of rapid and slow growth, opaque bands appear alternating with translucent bands. Therefore, the otoliths are constituted by different optically zones according to their structural appearance or light properties, e.g., translucent or opaque and the distinction among them allows to identify and count the rings through stereo-microscope observation [13].

Image J is an open source software for image analysis and processing, and allows user java written plug-ins to be added [11]. Thus, new plug-ins are easily spread and become available to a huge number of scientists with the purpose of improving fish age classification. A smart system for otolith age classification could provide input from different expert readers for the same otolith, and then adaptively learn to classify correctly the ring identification providing further information within each ring that may be useful for the expert readers' further research. The best automatic system should use the output of a camera with optical magnification, identify the otolith and determine its age by providing a value, its confidence intervals and precision to help the researchers evaluate and decide in a more objective way the age classification. In this study, the automatic system is still in development aiming to improve the age classification on blue whiting.

\section{Material and Methods}

\subsection{Sample Collection}

Fish samples of blue whiting were collected along the Portuguese coast during 2013, from January to December. Total length $(\mathrm{cm})$ and sex of all blue whiting sampled were recorded and the otoliths were removed from each fish. After, the otoliths were washed and stored dry. Sixty seven blue whiting otoliths were considered for this study. Otoliths were submerged in a $0.1 \%$ thymol solution $(1 \mathrm{~g}$ of thymol for 11 of filtered and distilled water) for approximately $24 \mathrm{~h}$. The whole otolith was immersed in oil and observed under reflected light against a black background in a stereomicroscope. The otoliths images acquisition was performed using the TNPC software (version 7.0) [9]. For age classification only one otolith of the sagittae pair was used. On the current study the left otolith was used. Age classification was made considering the number of translucent rings in the otolith; one translucent ring was equivalent to one year.

\subsection{Image Analysis}

A plug-in was developed in Java for the ImageJ software [11] which allowed counting the age rings in the otolith image files. On the left otolith of each pair a transect line crossing the otolith longer axis is drawn (Figure 1). 


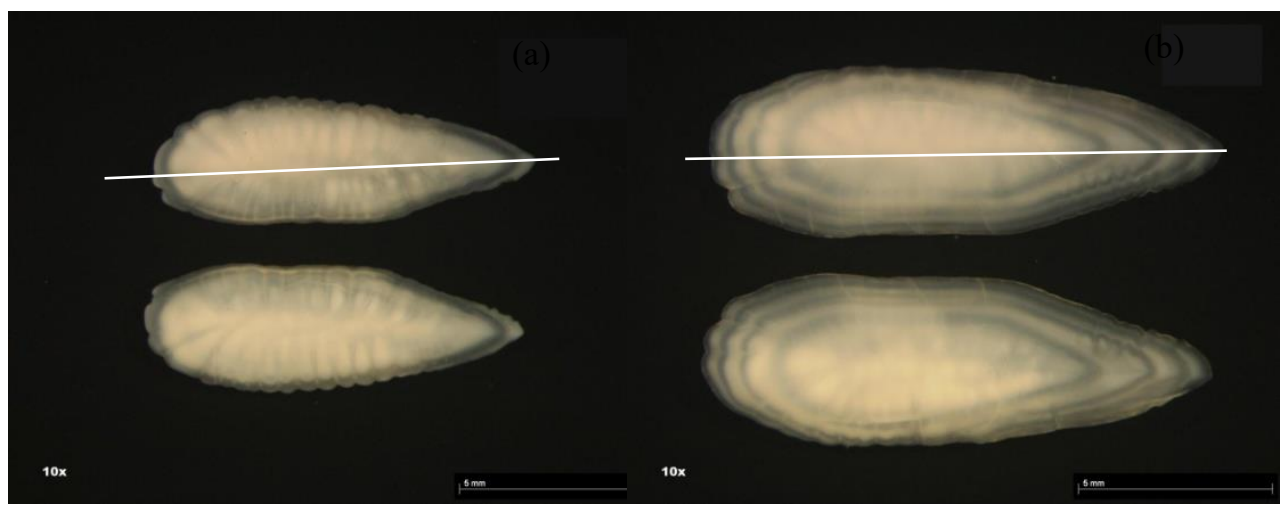

Fig. 1. Blue whiting left (top) (with the transect line) and right (bottom) otoliths from fishes with: (a) 1 year old and (b) 4 year old.

The automatic reading evaluation is based on the results from the otolith profile plotted along the longer axis (Figure 2).
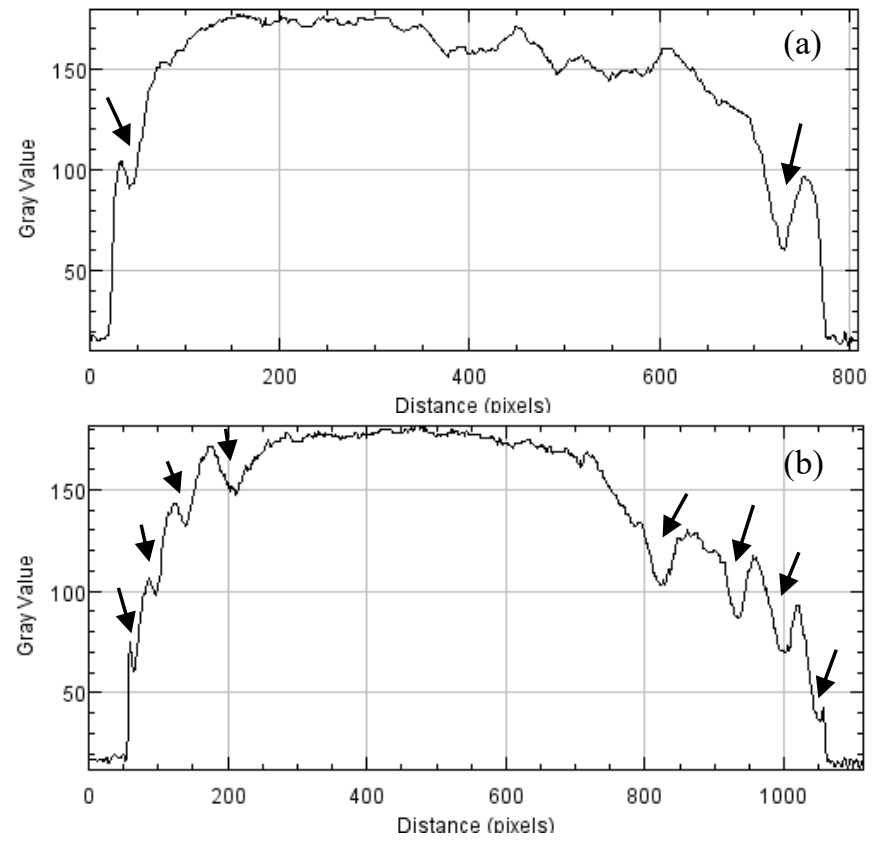

Fig. 2. Blue whiting left otolith profile along the long axis from fishes with: (a) 1 year old (Fig. 1a) and (b) 4 year old (Fig. 1b). The arrows indicate the rings position in the profile density plot.

The results from the automatic reading application were recorded and compared to the reader's age estimation. 


\subsection{Statistical Analysis}

A test of symmetry [14] for determining if significant differences existed between the ages by readers and the ages by Image J was applied. The test of symmetry uses a chisquare-type statistical test to determine if the age-agreement table is symmetric or not. If the age-agreement table is determined to be asymmetric then it can be concluded that there is a systematic difference in ages observed between readers and automatic ageing (ImageJ).

Two statistical indicators were used to measure the precision: (i) the average percent error (APE) [15] and (ii) the coefficient of variation (CV). The APE assumes that the standard deviation of the age estimates are proportional to the mean of the age estimates.

All statistical analyses and plots were performed using the packages FSA and ggplot2 from the statistical environment R [16].

\section{Results}

The length at age by sex was represented taking into account age classifications by readers (Figure 3a) and by ImageJ (Figure 3b). There are differences in the growth curves, namely the range of ages is higher in the Image $\mathrm{J}$ between 0 and 7 , while the range by readers varied from 1 to 6 .
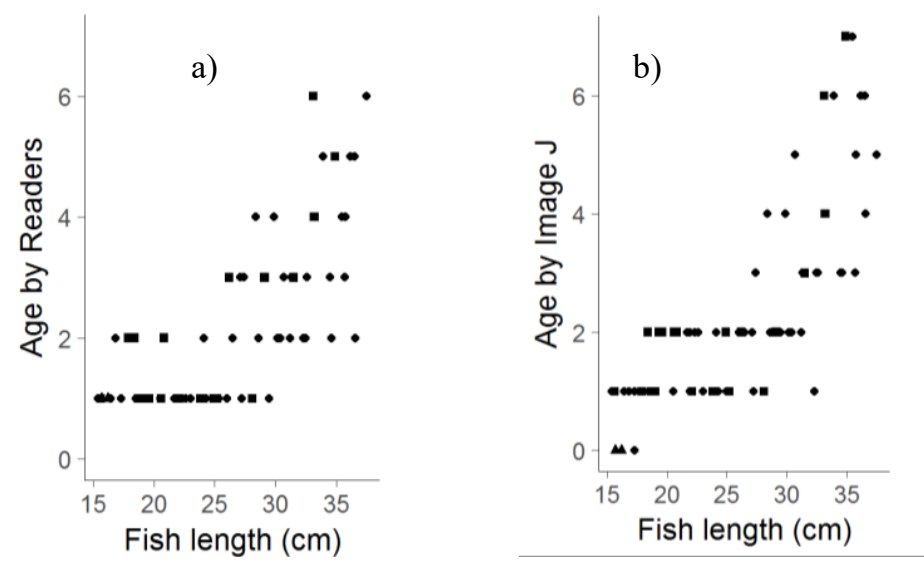

Fig. 3. Fish length $(\mathrm{cm})$ by age according to classifications by: a) readers and b) ImageJ application. Symbols correspond to fish's sex: $\boldsymbol{\Delta}$ indeterminate $^{1} ; \bullet$ females; and $\mathbf{\square}$ males.

The Hoenig test of symmetry $(\mathrm{p}=0.094)$ indicates that there are systematic differences in the assigned ages between readers and ImageJ. The ages estimation based on the automatic procedure are overestimated compared with the ages attributed from the

\footnotetext{
1 Denomination used when fish gonads show an earlier development stage and is not possible to assign a sex, i.e., to distinguish between female or male.
} 
readers (Figure 4). The same age was attributed by the two procedures in 36 otoliths, in a total of 67.

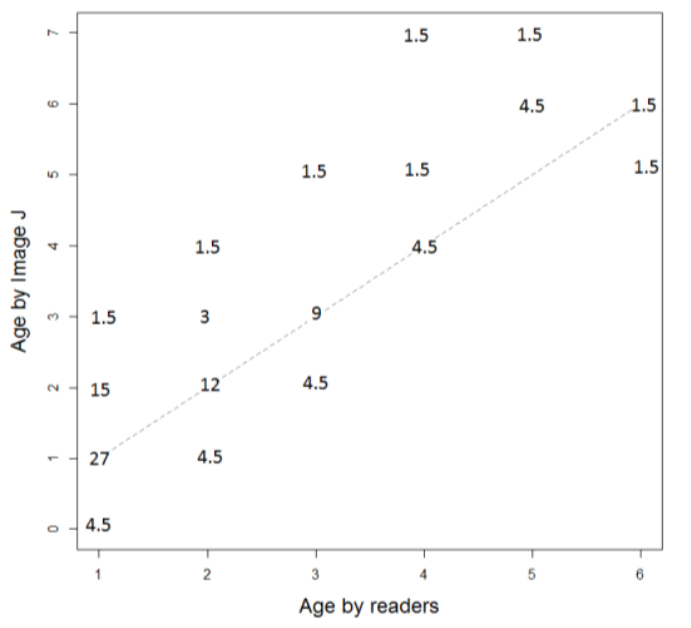

Fig. 4. Age-bias plot of estimations by readers and by ImageJ application. The dashed line represents the age-agreement between procedures. The values represent number of otoliths in percentage.

The precision methods reveal a low percentage of agreement (54\%) between the two procedures, with $\mathrm{CV}=21$ and $\mathrm{APE}=16$.

\section{Discussion and Conclusions}

The results from this study constitute the first application test performed in blue whiting otoliths from the Portuguese coast. In this test fish from a large length range and both sexes have been used, allowing identification of this procedure applicability in otoliths with different growth patterns. Differences were found in the age estimation from readers and using the ImageJ. Ages from readers take into account the time of the year, the type of otolith border and some subjectivity during ring count based on their experience. Ages are also estimated with the use of auxiliary information, such as fish size or sex which may bias the reader's interpretation [4]. There is a certain risk on use the fish size as auxiliary information on ageing, which could result in inability to detect changes on fish growth pattern due to the periods of starvation or to the climate changes, since temperature affects growth. The age estimation from Image J was only based on the ring count on the density profile plot which is an advantage. As an example, of this study results, a fish with length higher than $30 \mathrm{~cm}$, was classified as 1 by ImageJ and 2 years by the readers, this underestimation by the program could be due to readers based their classifications on the fish length and this fish could present a different growth pattern which was not detected in readers' classification. Notwithstanding this particular case, ImageJ is overestimating the ages in the majority of this study classifications, which could be due to a higher sensitivity of the 
software into recognizing patterns in the otolith density across the whole otolith section which could not be so evident through direct image observation or the irregular surface of some otoliths or the software counts is considering the denominated false rings $^{2}$ as valid rings. False rings are a common issue in blue whiting and a source of bias amongst the readers [18]. Although, since the age's estimations comparison were based on reader's classifications and not in validated ages those hypothesis need to be further evaluated. In order to validate the plug-in ImageJ estimations, it is important to repeat this test using otoliths from fishes in which the absolute age is known. There are also some basic age validations techniques, such as the relations between fish length and otolith length, fish length and otolith weight [2], which could be applied to the samples used on this study as a way to obtain more precision in estimations. This study constitutes a first approach to the blue whiting ageing validation and classification, the facility of incorporate macros on ImageJ will allow improving and calibrating the results until obtaining a good compromise between the automatic procedures and the fish growth.

The future steps, are applying this plug-in and provide the age estimations using the information of the otolith type of border and the time of the year when the fish was collected. Also, applying the ImageJ plug-in to otoliths with ages validated or in which the age estimation does not present any doubts. These tools will also be tested by experiment readers on blue whiting, as an exercise where the auxiliary information (fish length and sex) will not be provided, during the next international calibration workshop which will be held at Lisbon this June. The authors of this study truly believe that this new approach is a valid and useful application to help, the readers from the different countries, producing more precise and accurate fish age estimations on blue whiting.

Acknowledgments. We are thankful to the staff from Instituto Português do Mar e da Atmosfera (IPMA) who collected the blue whiting samples from their survey and from their commercial fishery. The samples used on this study were collected under the Portuguese Biological Sampling Programme (PNAB-EC Data Collection Framework) from IPMA. P. Gonçalves was funded by FCT through the fellowship SFRH/BD/88092/2012. This study had the support of Fundação para a Ciência e Tecnologia (FCT), through the strategic project UID/MAR/04292/2013 granted to MARE.

\section{References}

1. Tuset, V. M., Lombarte, A., Assis, C. A., 2008. Otolitos de peces del mediterráneo occidental y del atlántico central y nororiental. Sci. Mar., vol. 72, no. S1.

2. Campana, S.E., 2001. Accuracy, precision and quality control in age determination, including a review of the use and abuse of age validation methods. Journal of fish biology, 59(2), pp.197-242.

\footnotetext{
2 Any opaque area similar to an annual band but interrupted or without a "discontinuity" (if in the central area of the section) [17]
} 
3. Doering-Arjes, P., Cardinale, M. and Mosegaard, H., 2008. Estimating population age structure using otolith morphometrics: a test with known-age Atlantic cod (Gadus morhua) individuals. Canadian Journal of Fisheries and Aquatic Sciences, 65(11), pp.2342-2350.

4. Morison, A.K., Robertson, S.G. and Smith, D.C., 1998. An integrated system for production fish aging: image analysis and quality assurance. North American Journal of Fisheries Management, 18(3), pp.587-598.

5. Campana SE, Moksness E., 1991. Accuracy and precision of age and hatch date estimates from otolith microstructure examination. ICES Journal of Marine Science: Journal du Conseil. 1991 Nov 1;48(3):303-16.

6. Donald, D.B., Babaluk, J.A., Craig, J.F. and Musker, W.A., 1992. Evaluation of the scale and operculum methods to determine age of adult goldeyes with special reference to a dominant year-class. Transactions of the American Fisheries Society, 121(6), pp.792-796.

7. RATOC System Engineering Inc. Available: http://www.ratoc.co.jp/ENG/jiseki.html

8. Image Pro Plus Available: www.mediacy.com/imageproplus

9. TNPC Available:www.tnpc.fr.

10. Morison, A. K., Robertson, S. G., and Smith, D. C., 1998. An integrated system for production fish aging: image analysis and quality assurance. North American Journal of Fisheries Management, 18(3), 587-598.

11. N. I. of Health, "ImageJ." [Online]. Available: http://imagej.nih.gov/ij. [Accessed: 16Sep-2016].

12. ICES. 2016. Report of the Working Group on Widely Distributed Stocks (WGWIDE), 31 August-6 September 2016, ICES HQ, Copenhagen, Denmark. ICES CM 2016/ACOM: 16. $500 \mathrm{pp}$

13. Casselman, J.M., 1983. Age and growth assessment of fish from their calcified structures-techniques and tools. US Department of Commerce, National Oceanic Atmospheric Ad-ministration. National Marine Fisheries Service. Technical Report 8: 1-17.

14. Hoenig, J. M., Morgan, M. J. and Brown, C. A., 1995. Analysing differences between two age determination methods by tests of symmetry. Canadian Journal of Fisheries and Aquatic Systems 52:364-368.

15. Beamish, R. J., Fournier, D. A., 1981. A method for comparing the precision of a set of age determinations. Canadian Journal of Fisheries and Aquatic Sciences 38: 982-983.

16. R. D. C. Team, "R.” [Online]. Available: www.r-project.org. [Accessed: 16-Sep-2016].

17. Peres, M.B. and Haimovici, M., 2004. Age and growth of southwestern Atlantic wreckfish Polyprion americanus. Fisheries Research, 66(2), pp.157-169.

18. ICES. 2013. Report of the Workshop on the Age Reading of Blue Whiting, 10-14 June 2013, Bergen, Norway. ICES CM 2013/ACOM:53. 52 pp. 